\title{
REVIEW
}

\section{RISKY SINGLE-OCCASION DRINKING AMONGST YOUNG PEOPLE-DEFINITION, CORRELATES, POLICY, AND INTERVENTION: A BROAD OVERVIEW OF RESEARCH FINDINGS}

\author{
VERED MURGRAFF*, ANDREW PARROTT and PAUL BENNETT ${ }^{1}$
}

\begin{abstract}
Department of Psychology, University of East London, Romford Road, London E15 4LZ and ${ }^{1}$ University of Bristol and Gwent Psychology Services Health Psychology Unit, University of Bristol, 5 Priory Road, Bristol B58 1TN, UK

(Received 10 November 1997; in revised form 11 May 1998; accepted 14 June 1998)

Abstract - Risky single-occasion drinking (RSOD) has dire consequences upon health and well-being including unplanned pregnancies, sexually transmitted diseases such as HIV/AIDS, crime, and car accidents. The prevalence of RSOD among young people is alarming. Despite this, as yet, a review of existing literature on RSOD amongst young people is lacking. This article will provide an overview of this area of research focusing on the definition of RSOD, its prevalence among young people, health and behavioural effects of RSOD, the perceived risk of RSOD among young people, and interventions to reduce RSOD in young people. In addition, recommendations are made for health educators interested in reducing the incidence of RSOD in young people.
\end{abstract}

\section{INTRODUCTION}

Risky single-occasion drinking (RSOD) is considered the most common type of hazardous alcohol consumption among young people (Kellner et al., 1996; Quigley and Marlatt, 1996). Attempts to promote sensible drinking in young people have met with limited success (Foxcroft et al., 1997). Despite this, few efforts have been made to bring together the literature on RSOD in young people. The main purpose of this article is to outline the literature on RSOD in young people, and to make recommendations aimed at reducing this type of risky behaviour. It will examine the following issues: definitions of RSOD; prevalence of RSOD among young people; health and behavioural effects of RSOD; perceived risks of RSOD among young people; and interventions to reduce RSOD. The present article does not aim to review alcohol reduction in young people comprehensively (see Gorman, 1996; Foxcroft et al., 1997 for extensive reviews),

*Author to whom correspondence should be addressed. but rather aims at presenting a general overview of the various aspects of RSOD relevant to young people.

\section{DEFINITIONS OF RSOD}

There is no agreed definition of RSOD. Some researchers refer to RSOD as binge drinking, where binge drinking is defined by a certain cutoff point (e.g. Marlatt, 1994; Webb et al., 1996), others use frequent binge drinking (Schulenberg et al., 1996), heavy sessional drinking (Measham, 1996), and yet others use heavy episodic binge drinking (Nezlek et al., 1993). Several variations exist for the cut-off point used. One definition is five drinks per occasion (Hanson and Engs, 1992; Wechsler and Isaac, 1992; Marlatt, 1994); this is widely used in the USA, Canada (Smart and Walsh, 1993), and Australia (Polkinghorne and Gill, 1995). However, a less conservative definition is generally used in the UK, where RSOD is seen as $11 \mathrm{U}$ or more of alcohol per drinking occasion (Anderson and Plant, 1996). These definitions all fail to take into account gender differences in body mass and ethanol metabolism.

(C) 1999 Medical Council on Alcoholism 
Wechsler et al. (1994) therefore suggested genderspecific definitions of five or more drinks per episode for men and four or more drinks per episode for women. Similarly in the UK, researchers have suggested $10 \mathrm{U}$ per occasion for men and $7 \mathrm{U}$ for women (Webb et al., 1996). Empirical support for the use of either US or UK limits is lacking.

The lack of a unified definition for RSOD highlights our lack of knowledge on what constitutes safe or RSOD. Current knowledge about the relationship between alcohol consumption and psychosocial problems is insufficient to define adequately safety limits (Catarino, 1992; Health Education Authority, 1995a), and the suggested RSOD units are somewhat arbitrary. Thus most RSOD researchers do not provide empirical justification for their selected cut-off points (Marlatt et al., 1995; Measham, 1996; Schulenberg et al., 1996). One exception is Wechsler et al. (1995a), who suggested that their limit (5 or more drinks/occasion for men and 4 or more drinks/occasion for women) was indicative of a heavy-drinking lifestyle and of emergent alcohol-related problems. Despite the lack of evidence on what constitutes risk, single-occasion drinking is now targeted for health promotion programmes in the UK (Casswell, 1996). Specific daily limits are suggested, in addition to weekly limits (Department of Health, 1995). This concern follows the evidence that RSOD is associated with a number of negative short-term behavioural consequences (Health Education Authority, 1996) (these are described later). Furthermore, the evidence suggests that harm may be associated with single-occasion drinking at lower levels of drinking than previously thought harmful. Midanik et al. (1996), for example, found that there is a considerably increased risk of drinkdriving accidents with a consumption of one or fewer drinks a day (where drinking and driving is defined as driving after even 1 drink).

Further, there is an increased awareness that in order to reduce population levels of harm, the consumption by everybody needs to be modified. Although heavy consumers of alcohol contribute disproportionally to the incidence of alcoholrelated problems, it is the much larger segment of the population drinking moderately, who contribute the greater proportion of the alcoholrelated harm. Accordingly, intervention strategies aimed at reducing alcohol consumption are now targeted at the broad spectrum of drinkers, including lower risk or moderate drinkers (British Medical Association, 1995; Health Education Authority, 1995a). With the above issues in mind, UK governmental policies now define increased risk as following from $4 \mathrm{U}$ of alcohol or more a day for males and $3 \mathrm{U}$ of alcohol or more per day for women (Health Education Authority, 1996). Similarly, the British Medical Association recently recommended no more than three drinks per day for men and no more than two drinks per day for women (British Medical Association, 1995). This recent approach by health promotion professionals in the UK has been welcomed by many researchers in the alcohol and addiction field (e.g. Anderson, 1996) and is consistent with safe daily limits recommended by other governmental bodies such as in Australia and New Zealand (Health Education Authority, $1995 a)$.

\section{PREVALENCE OF RSOD IN YOUNG PEOPLE}

The prevalence of RSOD in young adults is high (e.g. Kellner et al., 1996; Quigley and Marlatt, 1996) and appears to be increasing (e.g. Health Education Authority, 1995b; Parker, 1995). RSOD often starts well before the legal drinking age (18 years in the UK). Anderson and Plant (1996) examined RSOD in a sample of 13-16year-olds in the UK. They found that $40 \%$ of the males and $32 \%$ of the females consumed at least $11 \mathrm{U}$ of alcohol on their last drinking occasion. In an Australian national survey of 16-17-year-olds, about $40 \%$ of the males and slightly fewer females occasionally practised RSOD (Cooney et al., 1993)

The prevalence of RSOD in the young also seems to increase with age. In a UK study, Measham (1996) conducted a survey on RSOD $(11+$ alcoholic U/occasion) in a sample of 14-16year-olds. In a 2-year longitudinal study, light sessional drinking (1-4 U) declined from 47 to $37 \%$, medium drinking (5-10 U) increased from 26 to $31 \%$, and heavy drinking (11-40 U) increased from 22 to $31 \%$. These heavy sessional drinking behaviours do appear to increase with age

RSOD also seems to continue on into young adulthood. A longitudinal study conducted on a national sample of the UK respondents at 16 and 
at 23 years showed that those who drank most at age 16 years were the most likely to drink heavily at 23 years (Ghodsian and Power, 1987). However, a 2-year longitudinal study conducted on a national sample of 18-24-year-olds in the USA (Schulenberg et al., 1996) showed that $6.7 \%$ of the respondents reported RSOD (defined as having 5 or more drinks in a row at least once a week) at every one of the four follow-up periods which were conducted over a period of 6 years; $11.7 \%$ reported RSOD at the start of the study, but decreased their RSOD to none at the last follow-up date, whereas $9.5 \%$ reported no RSOD at the start of the study, but increased their RSOD at followup four. The above authors concluded that there is a variation in the development of RSOD patterns into later adulthood. Apart from confirming the finding that, for some people early RSOD continues into later adulthood, the study provided information about other important patterns. For some drinkers, the pattern of RSOD is decreased in time, and yet for others, patterns of RSOD are increased over time, suggesting that the roots of temporary or long-term adulthood difficulties do not always lie in adolescence.

Although the extent to which early RSOD habits are carried over into young adulthood is unclear, young adults often show alarming levels of RSOD (Meilman et al., 1990; Harvard School of Public Health, 1995; Delk and Meilman, 1996). For example, in one USA study, $50 \%$ of male students (aged 18-25 years) reported drinking five or more drinks in a row and $39 \%$ of the females reported drinking four or more drinks in a row (Wechsler et al., 1995a). Nevertheless crossnational research does suggest higher consumption in the UK than elsewhere. For example, Delk and Meilman (1996) carried out a study on 18-25year-olds both in Scotland and in the USA. RSOD defined as five or more drinks in one sitting in the previous 2 weeks was reported by $62.2 \%$ of the Scottish students and by $40.4 \%$ of the US students. A further $31.4 \%$ of the Scottish and $16.3 \%$ of the Americans had engaged in RSOD three or more times in the previous fortnight.

\section{HEALTH AND BEHAVIOURAL EFFECTS OF RSOD}

Research on the constancy of drinking habits among young people may be helpful in identifying who is likely to engage in RSOD later on and subsequently be at increased risk of the long-term effects of excessive alcohol consumption. However, of additional interest are the specific risks associated with RSOD. These may take two forms: (1) the long-term health consequences of excess drinking; (2) the more immediate behavioural costs. Up to 40000 people a year in the UK are thought to die prematurely as a consequence of excessive alcohol intake (Royal College of General Practitioners, 1986). Cirrhosis of the liver is the disease most frequently associated with alcohol damage; however most deaths result from cancer (Anderson et al., 1993), with 3\% of all cancers being attributable to excess alcohol. Even more dramatically, a combination of smoking and high alcohol consumption results in a 44-fold increase in oesophageal cancer (Smith and Jacobson, 1988). The lack of adequate longitudinal studies to determine the relationship between patterns of alcohol consumption and the development of diseases does not enable a clear identification of the long-term risks associated with RSOD (as opposed to chronic heavy drinking). It is likely that cancer is not a result of RSOD, but rather chronic high alcohol intake. However, such health consequences may be associated with the long-term use of alcohol, and the longer one drinks excessively, the greater the increased risk for disease. It is therefore worrying that early RSOD among young people may form a precursor to long-term health problems.

Of further importance are the immediate negative consequences of excess consumption. Young people are over-represented in measures of alcohol-related harm (e.g. Quigley and Marlatt, 1996), and within this group, the risk rises according to the number of drinks consumed on each occasion (Kellner et al., 1996). The deleterious effects of alcohol on judgement are well known. Young people when drunk are more likely to have accidents, whether at home, at work, or on holiday (Health Education Authority, 1996). The effects of alcohol on judgement are particularly salient in the area of drinking and road accidents. Even a relatively small amount of alcohol can affect driving ability and judgement (Midanik et $a l ., 1996)$. For young and inexperienced drivers, the risk of having an accident is increased by a factor of 5 at the legal limit $(80 \mathrm{mg} / 100 \mathrm{ml}$ of blood) (Health Education Authority 1995b, p. 12). 
This highlights the need to address young people in drink-driving campaigns. Indeed many of the recent drink-driving campaigns, such as the 'at least we can still be mates' leaflet have addressed 20-29-year-olds specifically. These campaigns were found to be effective in reducing drinkdriving (Department of Transport, 1995). Further, market research shows that since 1979 the proportion of those who admitted drinking $6 \mathrm{U}$ of alcohol on one occasion in the previous week and driving fell from 31 to $9 \%$ (Department of Transport, 1995).

Young people often combine alcohol and sex. Bagnall and Plant (1991) reported that, in a cohort of 16-30-year-olds, $82 \%$ of the respondents reported drinking before engaging in sexual activity. Moreover, excessive alcohol consumption increases the likelihood of other risky behaviours such as unprotected sex (Morgan et al., 1990). Bagnall and Plant (1990) in a study of 25-26-yearold heterosexuals reported that respondents who reported a high frequency of combining alcohol and sex were rated seven times less likely to report regular use of condoms during vaginal intercourse. McEwan et al. (1992) reported that heavier drinkers were more likely to have unsafe sex, such as casual sex without a condom. These results suggest that alcohol consumption does affect the sexual behaviour of some young heterosexual people and that this might have implications for sexually transferred diseases, including HIV. Interventions aimed at reducing risky sexual practices should therefore aim to decrease excessive alcohol consumption in young people. Although studies of the association between excessive alcohol consumption and unsafe sexual practices do not address RSOD specifically, such association is likely to be highly implicated. This is because of the greater release of inhibitions at high-alcohol doses. Despite the association between drinking excessively and unprotected sexual intercourse, no causal relationship is yet established. Thus it is not clear whether a third variable such as arousal seeking mediates between these two risky behaviours. Correspondingly, it is not self-evident that interventions to reduce RSOD would be the most effective approach to reduce the adverse consequences of unsafe sex. Further, Donovan and McEwan (1995) in a review of the literature reported that the association between alcohol consumption and risky sex is stronger for heterosexual young people than for male gay populations. This indicates that recommendations for safer guidelines for alcohol consumption should address the various needs of specific populations, such as outlining risks associated with sex and alcohol in heterosexual drinkers where perceptions of the risks of contracting sexually-transmitted diseases are particularly low.

\section{IS RSOD CONSIDERED RISKY BY YOUNG PEOPLE?}

RSOD is generally not perceived as carrying risk and any adverse consequences are acceptable to many drinkers. In one British study, the authors reported that, although $65 \%$ of risky singleoccasion student drinkers were aware that their level of drinking was dangerous, only $7.5 \%$ wanted advice on safe drinking and only $5 \%$ wanted to drink less (File et al., 1994). In another UK study, a survey of alcohol use among college students in Scotland showed that both students (of whom $62.2 \%$ reported consuming 5 or more drinks in a sitting in the previous 2 weeks) and course administrators indicated that they did not find alcohol use by college students to be a problem. This was then confirmed by the city police sergeant, who reported that alcohol use posed little real threat to the public or students (Delk and Meilman, 1996). Of interest is that the immediate adverse consequences of RSOD may not serve to reduce its likelihood, as these consequences are simply not perceived as indicative of a drinking problem. Posavac (1993) reported that a sizeable minority of students failed to label risky behaviours associated with excessive drinking as problematic. Forty-two per cent of female students, for example, did not think that changes in sexual behaviour after drinking indicated drinking problems, while $45 \%$ did not view a monthly loss of memory after a party as indicating a drinking problem. A similar picture emerged elsewhere. In the USA, for example, few risky single-occasion drinkers consider themselves to be heavy drinkers. A national report by the Harvard School of Public Health (1995) showed that $91 \%$ of the women and $78 \%$ of the men who were rated as frequent risky single-occasion drinkers, considered themselves to be moderate or light drinkers.

In terms of recommendations to health educators, the low perceived risk of RSOD among 
young people indicates a need for greater awareness of its dangers. Until recently, the risks of RSOD were relatively ignored amongst health educators. Thus, the Health Education Authority $(1995 b)$ argued that its lack of emphasis on the dangers of alcohol and emphasis on dangers by unprotected sex, drugs, and smoking might encourage the consumption of alcohol among young people, as drinking may be considered as a 'safe' alternative. Further, the most frequently cited adverse health consequence of excess consumption, liver damage, may appear to be so remote that it confers no genuine threat to young people. Recent public education campaigns have, however, pointed out the dangers of RSOD (Health Education Authority, 1996). This new focus on RSOD is welcome, particularly since it emphasizes that those who engage in RSOD are the ones most likely to suffer harm.

\section{INTERVENTION PROGRAMMES AIMED AT REDUCING RSOD}

School- or college-based interventions constitute a substantial bulk of the interventions aimed at young people (Gorman, 1996; Foxcroft et al., 1997). Reviews of their relative effectiveness have generated some partial support (Hansen, 1992; Gorman, 1996; Foxcroft et al., 1997). This latter group reviewed the literature which included 33 studies classified as well-designed and adequatelyevaluated, of which the majority combined social skills training with knowledge-based education. Foxcroft et al. (1997) reported that 22 studies showed some significant reductions in drinking behaviour. One study included in Foxcroft et al.'s (1997) review, for example, reported a prevention programme which was partially effective in the short term (Gilchrist et al., 1987). In this study, a culturally tailored 10-session skills-enhancement programme involving a discussion of the myths concerning drinking, health education, peer lecturing about the factors which encourage alcohol use, the importance of making decisions about health, and communication skills was carried out. At a 6-month follow-up, the experimental group reported fewer instances of alcohol consumption than the control group. Further, intervention condition subjects were less likely to identify themselves as users of alcohol than controls. Two other studies included in the review by Foxcroft $e t$ al. (1997), namely those by Bagnall (1990) and Botvin et al. (1995), were found to be partially effective in the medium term. In Bagnall's (1990) study, respondents received educational intervention involving the provision of information about strengths of different alcoholic drinks, the risks of intoxication, media messages about alcohol, parental attitudes to drinking, and peer-group pressure. At 10-month follow-up, respondents reported lower self-reported consumption, both in terms of recency of self-reported drinking (those in the intervention group were less likely to have drunk alcohol in the last 7 days) and in terms of the amount they drank (the self-reported maximum consumption of the intervention group was lower than that of controls). Botvin et al. (1995) followed up several thousand US teenagers over 6 years after initial administration of a lifeskills training intervention involving a multimodel drug education programme. This consisted of 15 classes in the seventh grade, 10 booster sessions in the eighth grade and five booster sessions in the ninth grade, and covered general life skills and skills for resisting social influences to use drugs. They found significantly less selfreported drunkenness in the experimental group. Lower rates of alcohol use were reported in the 6-year follow-up in terms of monthly, weekly, number of drinks per occasion, and self-reported drunkenness.

In their review, Foxcroft et al. (1997) pointed out that, when studies are sorted according to their theoretical basis, there are no systematic differences between programmes which claimed success to those with no effect; most prevention programmes combined social skill training with knowledge-based education. Similarly, Gorman (1996) in a review of school-based social skills training for alcohol use prevention among adolescents concluded that the evidence is inconsistent and that interventions which were found to be effective do not vary in content substantially from those reporting no effectiveness. Gorman further commented that the limited support for such programmes is only to be expected when one considers the complex network of factors, ranging from the interpersonal to the sociocultural, that influences adolescents' alcohol use. This partial support for the various social-skills training programmes has led Gorman (1996) to call for refinement of preventative programmes in order to 
identify potentially effective components. One example of such refinement is the correction of erroneous beliefs about the prevalence of alcohol use (e.g. Hansen, 1993). For example, Haines and Spear (1996) designed a 5-year intervention programme to change college students' perceptions of drinking norms. The intervention was based on a media campaign designed to change student perception of the amount of RSOD (defined as consuming 6 drinks or more on 1 drinking occasion) consumed when partying. Haines and Spear (1996) conducted a major public information campaign to decrease the number of students who believed that drinking six or more drinks when partying is the normal practice which was presented to students in the form of display advertisements as well as weekly classified advertisements in their campus newspaper. Throughout the intervention period, the researchers also distributed fliers at students' events that highlighted actual drinking norms on campus. This intervention showed an $18.5 \%$ drop in the number of students who perceived RSOD as the norm (from 69.7 to $34.2 \%$ ) suggesting that changing college students' perceptions of drinking norms may lower the proportion of students who engage in RSOD. This finding is also consistent with other studies in the area (e.g. Hansen and Graham, 1991).

Perceived social norms may also be changed through modelling appropriate healthy norms (Donaldson et al., 1996; Bennett and Murphy, 1997). Here, peers may be used to influence informational norms through modelling healthy behaviours. They may also foster the development of assertion and resistance skills through vicarious learning from role play and behavioural modelling. Peers probably have more credibility as models than teachers, particularly in discussion of the use of illicit drugs (Perry et al., 1986). The relative effectiveness of such methods is revealed in reviews of the literature (Schaps et al., 1981; Coggans and Watson, 1995; Herrmann and McWhirter, 1997). These latter authors concluded that 'peer-led refusal and resistance skill training strategies appear to be highly effective across cultural contexts and settings and appear more efficacious than teacher-led refusal and resistance skill training'. Two points however need to be noted with regard to peer-led interventions. First, although these have been found to be either equivalent or better than teacher training in changing knowledge and attitudes towards alcohol, they are limited in their utility for reducing alcohol consumption. Second, some studies show that it is the peer tutors who gain (more than the tutees) in terms of knowledge, self-esteem and attitudes to school (Resnick and Gibbs, 1988).

In common with the aims of school- or collegebased interventions, other types of interventions, such as mass-media educational campaigns, warning labels and restrictions on commercial advertising of alcohol, are also by and large aimed at influencing intention, knowledge, attitude, and behaviour. Educational messages are often forwarded to the public in the mass media. Massmedia campaigns typically advocate 'moderate' alcohol use including switching to non-alcoholic drinks (Barber et al., 1989) and portraying the negative effects of alcohol, such as impaired sexual performance (Comiti, 1990). These were typically shown to increase awareness, but to have limited success in changing consumption (Bennett and Murphy, 1997). Another common theme in mass-media campaigns has been to avoid drinking and driving (Hewitt and Blane, 1984). These were shown to be relatively successful in reducing consumption (Moskowitz, 1989). Some sophisticated mass-media educational programmes, such as the 'Pssst . . . the really useful guide to alcohol' television series (Bennett et al., 1991), which involved modelling of appropriate drinking behaviour and behavioural change by people such as television and sport personalities and people attractive to a young audience, have evidenced small short-term shifts in behaviour. The limited utility of mass-media educational programmes, however, suggests that traditional educational programmes alone are unlikely to engender substantial long-term changes in patterns of consumption.

Despite codes of conduct which prohibit the targeting of young people in advertising, many alcohol advertisements remain attractive to young people. Aitken et al. (1988), for example, found that beer commercials were amongst the most popular commercials with children aged 13-14 years, with advertisements for Carling Black Label, Miller-Lite, and Fosters lagers surpassing the popularity of those for Coca Cola. Not only were these advertisements popular, they were seen by this age group as conferring positive social attributes, and served to reinforce under-age 
drinking. In addition, Aitkin and Block (1984) found that, in a sample of 12- to 17-year-olds, those with higher levels of exposure to advertising were more likely to approve of under-age drinking and drunkenness. While complete advertising bans may prove ineffective (Maynard, 1985), increased control over the targeting of alcohol advertising (and even its presentation in bottles) may prove necessary and effective.

Labelling beverage containers with warnings about the effects of alcohol on health is another method used in the USA to reduce alcohol consumption and alcohol-related harm. However, most of the evidence suggests no change in the perception of risk and only a few studies suggest behavioural changes which might be attributable to the warning label (Hilton, 1992; Edwards et al., 1994; Abel, 1998).

School-based education, public education, alcohol advertising restrictions, and labelling beverage containers are all methods aimed at changing the behaviour of the individual. However, it has been argued that, even if these are refined, alone they are unlikely to be effective without other environmental influences (Edwards et al., 1994, p. 180). Congruent with the latter methods, the World Health Organization (1988) has called for specific environmental policies to reduce the prevalence of a number of behaviours including excess alcohol consumption (see Bennett et al., 1992). This led the WHO to set up the European Alcohol Action Plan (EAAP) (World Health Organization, 1993), which aims to reduce overall alcohol consumption and combat high-risk behaviour. The EAAP proposes several areas for immediate action: (1) building a healthy alcohol public policy which would include developing an effective legislation on areas such as price and tax measures, controls on availability, and controls on advertising; (2) recognition of the importance of action at a community level, thus providing local settings and projects that promote health; (3) strengthening activity in primary health care, and self-help groups, and acting as an advocate for public health in local communities. The EAAP thus through the introduction of comprehensive policies and recognition of the importance of multi-sectoral action has provided a framework for governmental and non-governmental action, policy implementation, and programmes at both national and local level
(Anderson, 1996).

In addition to the above EAAP recommendations, the impact of increasing the prices of alcoholic drinks may help in reducing alcohol consumption (Grossman et al., 1994). Laixuthai and Chaloupka (1993) found that higher beer prices substantially reduce the frequency of youth alcohol consumption and RSOD drinking episodes among youths. When comparing the sensitivity of young peoples' heavy drinking to that of adults, Kenkel (1993) found that heavy alcohol consumption in all age groups was inversely related to the price of beverages. Moreover, heavy drinking by younger persons was more sensitive to price than was heavy drinking by adults, with heavy drinking by young women much more sensitive to price than heavy drinking by young men. The benefits of this approach within this population were not only found to relate to reduction in consumption, but also to reduction in alcohol-related harm, particularly to the reduction in incidents of drinking and driving (Grossman et al., 1995). One simple method of reducing consumption among young people may be to increase alcohol taxation. Research shows that alcohol taxation is an effective and readily available environmental policy instrument which can be applied to save lives and reduce harm (Edwards et al., 1994; Ponicki et al., 1997). Higher beer taxes significantly reduce drinking frequency both for frequent and infrequent young drinkers (16-21 years) (Grossman et al., 1987). A more subtle approach may be to vary the price according to its alcohol content. Riley (1987), for example, suggested that advantageous pricing of 'mid-alcohol' drinks may make these more attractive. He further noted that a high proportion of high male drunk drivers had alcohol levels only minimally above the legal limit. Encouraging consumption of mid-alcohol drinks, he argued, may move the majority of presently offending young drivers to within the legal limits.

The importance of providing settings that promote health outlined in the EAAP is also demonstrated in studies of the effects of both limiting access to alcohol and availability of alcohol on consumption by young people. Evaluation of the limitation of physical access to alcohol, such as enactment of a minimum legal drinking age, restrictions of hours or days of sale, and policies on number, type or location of sales 
outlets, which together form a coherent alcohol control policy show a significant contribution to the prevention of alcohol problems within both moderate and heavy drinkers (Edwards et al., 1994, pp. 125-151). Ryan and Mosher (1993) have evaluated environmental interventions aimed at reducing heavy drinking in college students carried out in the USA pertaining to marketing practices. These include: (1) greater enforcement of existing laws governing drinking locations such as 'Daytona Beach's no alcohol on the beach regulation'; (2) the enactment of new regulations such as 'Palm Springs' ordinance restricting poolside drinking to certain periods'; (3) the restriction of activities that have drinking as a focus such as beer-sponsored concerts; (4) the request that retailers discontinue marketing practices that encourage heavy drinking, such as happy hour discounts. In their evaluation, the above authors argued that the controls instituted on alcohol consumption have dramatically reduced alcoholrelated harm. The US General Accounting Office (1987), in a review of studies about the consequences of reducing the minimum drinking age on alcohol-related harm, concluded that there is solid evidence that increasing the minimum age for purchasing alcohol reduced the number of alcohol-involved traffic accidents for young people who were below 21 years old. This finding was also consistent with findings elsewhere such as in Canada (Bako et al., 1976).

Two strategies at the point of service aimed at responsible beverage service may serve to either reduce the supply of alcohol to young people or to discourage RSOD. The first adopts an American model called 'server intervention'. This method involves training bar workers to identify customers who are drinking excessively and to develop skills to deal with such customers, including offering food or alternative drinks or discussing the catastrophic consequences that can result from drinking and driving. Reviews of this method have shown it to be effective in reducing excessive alcohol consumption (e.g. Gliksman and Single, 1988; Saltz, 1993). This is a particularly effective method where it is against the law to serve the 'obviously intoxicated' and where the providers of alcohol may themselves be sued if the person subsequently is involved in damages consequent to their alcohol consumption. The support, however, of the alcohol service management through its written and unwritten policies is vital to responsible alcohol service (McKnight, 1996). It may be less successful in a British context, where no such laws exist and there is a substantial culture of group drinking in 'rounds'. Here, negotiation by bar staff to reduce consumption with the purchaser may be overwhelmed by the demands of fellow drinkers to achieve the opposite effect. A potentially more powerful method used in the UK was reported by Jeffs and Saunders (1983). They examined the effectiveness of high-profile policing in public houses and clubs in an English seaside resort for one summer. The licensees and police agreed to work together to ensure that the law particularly relating to under-age drinking and serving alcohol to the already intoxicated was being observed. During the summer, the selected premises were visited regularly by uniformed police officers who amicably, but very conspicuously checked the under-age drinking and the presence of persons who were the worse for drink. This exercise significantly reduced the extent of alcohol-related crime over this period, in comparison to that of previous years and to a control town.

\section{GENERAL CONCLUSIONS}

The high prevalence of RSOD in young people calls for urgent action. One such action is the recent shift in public education from weekly to daily limits in the UK. Although it is too soon to tell whether this transition would be effective in reducing RSOD in young people, it is likely to contribute to heightened awareness of the risks associated with RSOD. It is also possible that the earlier focus on daily limits in other countries, such as the USA, has contributed to the lower prevalence of RSOD in young people.

Difficulties with using a whole-population definition of RSOD are apparent. The lack of consideration of individual differences in terms of bodily weight where the ratio of blood to alcohol differs from one individual to another and may therefore affect intoxication thresholds is one example. The neglect of past drinking experience where the importance of style, pattern, and spacing of drinking affects intoxication thresholds as well as behavioural actions while under the influence of alcohol is another. Furthermore, this definition fails to deal with the importance of the drinking context, e.g. consuming seven to 10 drinks at 
home is considerably less risky than doing so and then driving a car. In support of the drinking context, the setting of legal limits in the USA for the prevention of drink-driving in young drivers who are at risk due to both their inexperienced driving and their inexperienced drinking was found to reduce traffic accidents (e.g. Drummond et al., 1987). A further example is that the focus on daily limits may encourage a wider population and spur light drinkers to drink up to the stated limits. The majority of the population are likely to be drinking below any promulgated safe limit and therefore there is the danger of encouraging them to increase their consumption. Furthermore, it has been argued that the new daily limits have produced the misconception that the advised maximum weekly intake has increased from $21 \mathrm{U}$ per week to $28 \mathrm{U}$ and thus may ironically increase RSOD (Edwards, 1996). The latter is supported by Wright and Cameron (1997), who showed that respondents who consume 7-21 U of alcohol per week are less likely to engage in RSOD (defined as $8 \mathrm{U} /$ drinking occasion) than those who consume between 22 and $28 \mathrm{U}$ of alcohol weekly. Any new daily limits thus would need to be supplemented with a clarification that these do not warrant a change in existing weekly limits.

Despite these problems, the shift towards a definition of safer single-occasion drinking in the $\mathrm{UK}$ is welcome. The set limits are useful in helping individuals monitor their drinking, especially considering the common belief among young drinkers that RSOD is not particularly risky. The reduction in RSOD will ultimately depend on the promotion of a message that RSOD is harmful, the emphasis on the association between behaviour and risks, the provision of the necessary skills needed in drinking situation negotiations, as well as on changes in the social norms around RSOD. However, it is unlikely that individual-based interventions will be successful, unless these are combined with changes in the wider social environment. Increasing the price and reducing the availability of alcohol were found to be particularly effective in reducing alcohol consumption in young people.

Attempts to reduce RSOD are still in their infancy, especially in the UK, where it is only recently that we have become aware of the neglect of single-occasion drinking in campaigns to reduce drinking. There is work to be done before we can confidently argue that we have limits which are accepted and seen as useful for monitoring alcohol consumption by the drinking population as a whole. Drinkers' acceptability of the new limits need to be established by studies showing the attitudes and beliefs of drinkers towards them as well as the effect of setting up these limits on subsequent consumption. Furthermore, the validity of the new limits in reducing alcohol consumption and alcohol-related harm needs to be established. The long-term consequences of RSOD is another open question, for example, how does it differ from excessive regular drinking? This of course is a difficult question to research, as it requires longitudinal studies which would follow individuals throughout life. Furthermore, we need an environment free of drug use and smoking without promoting alcohol as the safe alternative for young people as well as the recognition that even low levels of drinking are harmful. The aim, thus, appears to be a shift towards training a generation of light drinkers.

\section{REFERENCES}

Abel, E. L. (1998) Prevention of alcohol abuse-related birth defects - Public education efforts. Alcohol and Alcoholism 33, 411-416.

Aitken, P. P., Leathar, D. A. and Scott, A. C. (1988) Ten to sixteen year olds' perceptions of advertisements for alcoholic drinks. Alcohol and Alcoholism 23, 491-500.

Aitkin, C. K. and Block, M. (1984) The effects of alcohol advertising. In Advances in Consumer Research, Kinnear, T. C. ed., pp. 688-693. Association for Consumer Research, Provo, UT.

Anderson, K. and Plant, M. (1996) Abstaining and carousing: substance use among adolescents in the Western Isles of Scotland. Drug and Alcohol Dependence 41, 189-196.

Anderson, P. (1996) Guidelines on sensible drinking. Addiction 91, 25-33.

Anderson, P., Cremona, A., Paton, A., Turner, C. and Wallace, P. (1993) The risk of alcohol. Addiction 88 , 1493-1508.

Bagnall, G. (1990) Alcohol education for 13 year olds - does it work? results from a non-controlled evaluation. British Journal of Addiction 85, 89-96.

Bagnall, G. and Plant, M. A. (1990) Alcohol, drugs and AIDS related risks: results from a prospective study. AIDS Care 2, 309-317.

Bagnall, G. and Plant, M. A. (1991) HIV/AIDS risks, alcohol and illicit drug use among young adults in areas of high and low rates of HIV infection. AIDS Care 3, 355-361.

Bako, G., MacKenzie, W. C. and Smith, E. S. O. (1976) 
The effect of legislated lowering of the drinking age on fatal highway accidents among young drivers in Alberta, 1970-1972. Canadian Journal of Public Health 67, 161-163.

Barber, J. G., Bradshaw, R. and Walsh, C. (1989) Reducing alcohol consumption through television advertising. Journal of Consulting and Clinical Psychology 57, 613-618.

Bennett, P. and Murphy, S. (1997) Psychology and Health Promotion. Open University Press, Buckingham.

Bennett, P., Smith, C. and Nugent, Z. (1991) Patterns of drinking in Wales. Alcohol and Alcoholism 26, 367374.

Bennett, P., Murphy, S. and Bunton, R. (1992) Preventing alcohol problems using healthy public policy. Health Promotion International 7, 297-306.

Botvin, G. J., Baker, E., Dusenbury, L., Botvin, E. M. and Diaz, T. (1995) Long term follow-up results of a randomised drug abuse prevention trial. Journal of the American Medical Association 273, 1106-1112.

British Medical Association (1995) Alcohol: Guidelines on Sensible Drinking. British Medical Association, London.

Casswell, S. (1996) Drinking guidelines offer little and above the much needed public health policies. In Commentaries: guidelines on sensible drinking. Addiction 91, 25-33.

Catarino, P. A. (1992) Is there a safe level of drinking?: a student's view. Alcohol and Alcoholism 27, 465470.

Coggans, N. and Watson, J. (1995) Drug education: approaches, effectiveness, and delivery. Drugs. Education, Prevention and Policy 2, 211-224.

Comiti, V. P. (1990) The advertising of alcohol in France. World Health Forum 11, 242-245.

Cooney, A., Dobbinson, S. and Flaherty, B. (1993) Drug Use by NSW Secondary School Students - 1992 Survey. New South Wales Health, New South Wales, Australia.

Delk, E. and Meilman, P. W. (1996) Alcohol use among college students in Scotland compared with norms from the United States. Journal of American College of Health 44, 274-281.

Department of Health (1995) Sensible Drinking: The Report of an Inter-Departmental Working Group. Department of Health, Wetherby.

Department of Transport (1995) Drinking and Driving. Department of Transport, London.

Donaldson, S. I., Sussman, S., MacKinnon, D. P. Severson, H. H., Glynn, T., Murray, D. and Stone, E. (1996) Drug abuse prevention programming: do we know what content works? American Behavioural Scientist 39, 868-883.

Donovan, C. and McEwan, R. (1995) A review of the literature examining the relationship between alcohol use and HIV-related sexual risk taking in young people. Addiction 90, 319-328.

Drummond, A. E., Cave, T. C. and Healy, D. J. (1987) The risk of accident involvement by time of week as assessment of the effects of zero BAC legislation and the potential of driving curfews. In Young
Drivers Impaired by Alcohol and Other Drugs, Benjamin, T. ed., pp. 385-398. Royal Society of Medicine Services, London.

Edwards, G. (1996) Sensible drinking. British Medical Journal 312, 1.

Edwards, G., Anderson, P., Babor, T. F., Casswell, S., Ferrence, R., Giesbrecht, N., Godfrey, C., Holder, H., Lemmens, P., Makela, K., Midalik, L., Norstrom, T., Osterberg, E., Romelsjo, A., Room, R., Sipora, J. and Skog, O.-J. (1994) Alcohol Policy and the Public Good. Oxford University Press, Oxford.

File, S. E., Mabutt, P. S. and Shaffer, J. (1994) Alcohol consumption and lifestyle in medical students. Journal of Psychopharmacology 8, 22-26.

Foxcroft, D. R., Lister-Sharp, D. and Lowe, J. (1997) Alcohol misuse prevention for young people: a systematic review reveals methodological concerns and lack of reliable evidence for effectiveness. Addiction 5, 531-537.

General Accounting Office (1987) Drinking age laws: an evaluation synthesis theory and adolescents' perception of exercise. Journal of Applied Social Psychology 22, 55-69.

Ghodsian, M. and Power, C. (1987) Alcohol consumption between the ages of 16 and 23 in Britain: a longitudinal study. British Journal of Addiction 82, 175-180.

Gilchrist, L. D., Schinke, S. P., Trimble, J. R. and Cvetkovich, G. E. T. (1987) Skills enhancement to prevent substance abuse among American Indian adolescents. International Journal of the Addictions 22, 869-879.

Gliksman, L. and Single, E. (1988) A field evaluation of a server intervention program: accommodating reality. Paper presented at the Canadian Evaluation Society Meeting, Montreal.

Gorman, D. M. (1996) Do school based social skills training programs prevent alcohol use among young people? Addiction Research 4, 191-210.

Grossman, M., Coate, D. and Gregory, M. (1987) Price sensitivity of alcoholic beverages in the United States. In Control Issues in Alcohol Abuse Prevention: Strategies for States and Communities, Harold, H. and Holder, H. H. eds. JAI Press, Greenwich, CT.

Grossman, M., Chaloupka, F. J., Saffer, H. and Laixuthai, A. (1994) Effects of alcohol price policy on youth: a summary of economic research. Journal of Research on Adolescence 4, 2.

Grossman, M., Chaloupka, F. J. and Ismail, S. (1995) An Empirical Analysis of Alcohol Addiction: Results from Monitoring the Future Panels. National Bureau of Economic Research Working Paper Number 5200, July, USA.

Haines, M. and Spear, S. (1996) Changing the perception of the norm: a strategy to decrease binge drinking among college students. Journal of American College of Health 45, 134-140.

Hansen, W. B. (1992) School-based substance abuse prevention: a review of the state of the art in curriculum, 1980-1990. Health Education: Theory and Practice 7, 403-430.

Hansen, W. B. (1993) School-based alcohol prevention 
programs. Alcohol, Health and the Research World 17, 54-60.

Hansen, W. B. and Graham, J. W. (1991) Preventing alcohol, marijuana, and cigarette use amongst adolescents: peer pressure resistance training versus establishing conservative norms. Preventive Medicine 20, 414-430.

Hanson, D. J. and Engs, R. C. (1992) College students' drinking problems: a national study, 1982-1991. Psychological Reports 71, 39-42.

Harvard School of Public Health (1995) Binge Drinking on American College Campuses: a New Look at an Old Problem. College Alcohol Study, Harvard School of Public Health, Department of Health and Social Behaviour, Harvard, MA.

Health Education Authority (1995a) Sensible Drinking: The Report of an Inter-Departmental Working Group. Department of Health, Wetherby.

Health Education Authority (1995b) Young People and Alcohol: Research Findings. Health Education Authority, London.

Health Education Authority (1996) Think about a Drink: There's More to a Drink than You Think. Health Education Authority, London.

Herrmann, D. S. and McWhirter, J. J. (1997) Refusal and resistance skills for children and adolescents: A selected review. Journal of Counselling and Development 75, 177.

Hewitt, L. E. and Blane, H. T. (1984) Prevention through mass media communication. In Prevention of Alcohol Abuse, Miller, P. M. and Nirenberg, T. D. eds, pp. 281-323. Plenum Press, New York.

Hilton, M. E. (1992) Perspectives and prospects in warning labels research. Paper presented at 18th Annual Alcohol Epidemiology Symposium, Toronto, 30 May-5 June.

Jeffs, B. W. and Saunders, W. M. (1983) Minimising alcohol related offences by enforcement of the existing licensing legislation. British Journal of Addiction 78, 67-77.

Kellner, F., Webster, I. and Chanteloup, F. (1996) Describing and predicting alcohol use-related harm - an analysis of the Yukon alcohol and drug survey. Substance Use and Misuse 31, 1619-1638.

Kenkel, D. S. (1993) Prohibition versus taxation: reconsidering the legal drinking age. Contemporary Policy Issues 11, 48-57.

Laixuthai, A. and Chaloupka, F. J. (1993) Youth alcohol use and public policy. Contemporary Policy Issues 11, 70-81.

Marlatt, G. A. (1994) Harm reduction for alcohol problems: reducing binge drinking in high risk youth. Paper presented at the International Conference on the Reduction of Drug Related Harm, Toronto, March, 1994.

Marlatt, G. A., Baer, J. S. and Larimer, M. (1995) Preventing alcohol abuse in college students: a harm reduction approach. In Alcohol Problems Amongst Adolescents, Boyd, G. M., Howard, J. and Zucker, R. A., eds. Lawrence Erlbaum, Hillsdale, NJ.

Maynard, A. (1985) The role of economic measures in preventing drinking problems. In The Misuse of
Alcohol: Crucial Issues in Dependence Treatment and Prevention, Heather, N., Robertson, I. and Davies, P., eds, Croom Helm, London.

McEwan, R. T., McCallum, A., Bhopal, R. S. and Madhok, R. (1992) Sex and the risk of HIV infection: the role of alcohol. British Journal of Addiction 87, 577-584.

McKnight, A. J. (1996) Server intervention to reduce alcohol involved traffic crashes. Alcohol, Health, and Research World 20, 227.

Measham, F. (1996) The 'big bang' approach to sessional drinking: changing patterns of alcohol consumption amongst young people in north west England. Addiction Research 4, 283-299.

Meilman, P. W., Gaylor, M. S., Turco, J. H. and Stone, J. E. (1990) Drug use among college undergraduates - current use and trends. International Journal of the Addictions 25, 1025-1036.

Midanik, L. T., Tam, W. T., Greenfield, T. K. and Caetano, R. (1996) Risk functions for alcohol related problems in one 1988 US national sample. Addiction 91, 1427-1437.

Morgan, R., Plant, M. A. and Plant, M. L. (1990) Alcohol, AIDS risks and sex industry clients: results from a Scottish study. Drug and Alcohol Dependence 26, 265-269.

Moskowitz, J. M. (1989) The primary prevention of alcohol problems: a critical review of the research literature. Journal of Studies on Alcohol 50, 54-88.

Nezlek, J. B., Pilkington, C. J. and Bilbro, K. G. (1993) Moderation in excess: binge drinking and social interaction among college students. Journal of Studies on Alcohol 55, 342-251.

Parker, H. (1995) Youth culture and the changing patterns of drinking by young people. In Alcohol and the young, NCB/Alcohol Concern Conference 14 December, delegates' pack. National Children Bureau, London.

Perry, C. L., Klepp, K. I. and Halper, A. (1986) A process evaluation study of peer leaders in health education. Journal of School Health 56, 62-67.

Polkinghorne, H. and Gill, T. (1995) 'Riding the tiger'; lessons from a health promotion activity aimed at reducing the use of alcohol by youth. Drug and Alcohol Review 14, 405-409.

Ponicki, W., Holder, H. D., Gruenewald, P. J. and Romelsjo, A. (1997) Altering alcohol price by ethanol content: results from a Swedish tax policy in 1992. Addiction 92, 859-870.

Posavac, E. J. (1993) College students' views of excessive drinking and the University's role. Drug Education 23, 237-245.

Quigley, L. A. and Marlatt, G. A. (1996) Drinking among young adults - prevalence, patterns and consequences. Alcohol Health and Research World 20, 185-191.

Resnick, H. and Gibbs, J. (1988) Types of peer program approaches. In Adolescent Peer Pressure; Theory Correlates and Program Implications for Drug Abuse Prevention, US Department of Health and Human Services, Rockville, MD.

Riley, D. (1987) Drink-driving and the alcohol beverage 
industry: will reducing per capita consumption solve the problem in the United Kingdom? Accident Analysis and Prevention 19, 449-462.

Royal College of General Practitioners (1986) Alcohol - A Balanced View. Report from General Practice. Royal College of General Practitioners, London.

Ryan, B. E. and Mosher, J. F. (1993) Spring break, alcohol promotions and community responses. In Experiences with Community Action Projects: New Research in the Prevention of Alcohol and Other Drug Problems, Greenfield, T. K. and Zimmerman, R. eds, US Department of Health and Human Services, Washington, DC.

Saltz, R. F. (1993) The introduction of drum shop legislation in the United States and the advent of server training. Addiction 88 (Suppl.), 95S-103S.

Schaps, E., DiBartolo, R., Moskowitz, J., Palley, C. S and Churgin, S. (1981) A review of 127 drug abuse prevention program evaluations. Journal of Drug issues 11, 17-43.

Schulenberg, J., O’Malley, P., Backman, J. G., Wadsworth, K. N. and Johnston, L. D. (1996) Getting drunk and growing up: trajectories of frequent binge drinking during the transition to young adulthood. Journal of Studies on Alcohol 57, 289-303.

Smart, R. G. and Walsh, G. W. (1993) Do some types of alcoholic beverages lead to more problems for adolescents? Journal of Studies on Alcohol 56, 3538.

Smith, A. and Jacobson, B. (1988) The Nation's Health. A Strategy for the 1990s. King's Fund Centre,
London.

Webb, E., Ashton, C. H., Kelly, P. and Kamali, F. (1996) Alcohol and drug use in UK university students. Lancet 348, 921-925.

Wechsler, H. and Isaac, N. (1992) 'Binge' drinkers at Massachusetts colleges. Journal of the American Medical Association 267, 2929-2931.

Wechsler, H., Davenport, A., Dowdall, G., Moeykens, B. and Castillo, S. (1994) Health and behavioural consequences of binge drinking in college. Journal of the American Medical Association 272, 16721677.

Wechsler, H., Dowdall, G. W., Davenport, A. and Castillo, S. (1995a) Correlates of college students' binge drinking. Journal of the American College of Public Health 85, 921-926.

Wechsler, H., Moeykens, B., Davenport, A., Castillo, A. and Hansen, J. (1995b) The adverse impact of heavy episodic drinkers on other college students. Journal of Studies on Alcohol 56, 628-634.

World Health Organization (1988) Towards Healthy Public Policies on Alcohol and Other Drugs. Consensus statement proposed by WHO Expert Working Group, Sydney-Canberra, 24-31 March 1988.

World Health Organization (1993) European Alcohol Action Plan. World Health Organisation, Europe Regional Office, Copenhagen.

Wright, N. R. and Cameron, D. (1997) A pilot study of prospectively recorded drinking patterns among British men who habitually drink 1-4 units of alcohol per day. Alcohol and Alcoholism 32, 777-778. 